\title{
Association Between Operation Duration of Total Knee Arthroplasty and Risk of Blood Transfusion Events: A Secondary Analysis Based on Cohort Study in Singapore
}

Bo Liu

The Affiliated Hospital of Qingdao University

Yue $\mathrm{He}$

The Affiliated Hospital of Qingdao University

Junpeng Pan

The Affiliated Hospital of Qingdao University

Zhijie Wang ( $\sim$ simonwang1969@163.com )

The Affiliated Hospital of Qingdao University https://orcid.org/0000-0002-4944-1750

\section{Research Article}

Keywords: Association, TKA, Operation Duration, Blood Transfusion, A Secondary Analysis

Posted Date: December 6th, 2021

DOI: https://doi.org/10.21203/rs.3.rs-1119129/v1

License: (c) (1) This work is licensed under a Creative Commons Attribution 4.0 International License.

Read Full License 


\section{Abstract}

\section{Background}

The purpose of our research is to explore the association between operation duration and the risk of blood transfusion in the patients undergoing TKA.

\section{Methods}

This study was a secondary analysis based on the data of a single-center retrospective cohort study in Singapore. The independent variable was the operation duration, and the dependent variable was the risk of blood transfusion events in the perioperation. we analyzed the risk factors of blood transfusion in the Perioperative period by univariate logistic regression, then, multivariable logistic regression analysis was performed adjusting for variables that might affect the operation duration of TKA and the risk of blood transfusion events. Additional analyses examined this association by the subgroup analysis by using stratified multivariate logistic regression models.

\section{Results}

Among 2,622 patients, 153 (5.8\%) had blood transfusion in perioperative period. The older (OR=1.051 ,95\% Cl:1.030, 1.073), the lower BMI (OR=0.939,95\% Cl: 0.903,0.976), the lower $\mathrm{Hb}(\mathrm{OR}=0.603,95 \% \mathrm{Cl}$ : $0.5416 .132)$, the $D M$ on insulin $(\mathrm{OR}=2.542,95 \% \mathrm{Cl}: 1.054,6.132)$, the Bilateral TKA(OR=3.202, $95 \% \mathrm{Cl}: 2.087$, 4.913), the within $\mathrm{CHF}(\mathrm{OR}=4.600,95 \% \mathrm{Cl}: 1.685,12.563)$, the $\mathrm{Cr} \geq 2 \mathrm{mg} / \mathrm{dl}(\mathrm{OR}=7.246,95 \% \mathrm{Cl}: 2.739$, 19.166), the higher ASA status (OR=6.439, 95\% Cl:2.403, 17.249), the higher risk of blood transfusion $(\mathrm{P}<0.05)$. The operation duration was positively correlated with perioperative blood transfusion. We demonstrated that the risk of blood transfusion increased by $1.1 \%$ for 1 -minute increase in operation duration $(\mathrm{OR}=1.011,95 \% \mathrm{Cl}: 1.004,1.018)$.

\section{Conclusion}

Our research shows that the longer the TKA operation duration, the higher the incidence of blood transfusion. The risk of blood transfusion events increases by $66 \%$ for every 1 -hour increase in operation duration. Compared with patients with operation duration $\$ 100$ minutes, patients with operation duration more than 100 minutes have an increased risk of blood transfusion events by $56.8 \%$.

\section{Introduction}

Total knee arthroplasty (TKA) is an effective method for the treatment of end-stage knee osteoarthritis, which can significantly relieve patients' pain and promote functional recovery[1,2]. Patients receiving TKA often need blood transfusion due to excessive blood loss, large joint cavity, joint swelling and other reasons $[3,4]$, while blood transfusion will increase the risk of postoperative adverse reactions in patients receiving TKA, such as perioperative sepsis, pneumonia, venous thromboembolism and even death[5-8]. Studies have shown that the incidence of blood transfusion in TKA is approximately $3.5 \%-18.5 \%[9]$. 
Reducing blood transfusion not only mitigates adverse reactions after TKA, but also lowers the risk of complications such as infection and body fluid overload [10]. In addition, lowering the incidence of blood transfusion can also effectively decrease the treatment cost of patients [11]. Therefore, it is necessary to minimize the risk of perioperative blood transfusion in TKA patients.

There are many factors related to perioperative blood transfusion in TKA patients, such as $\mathrm{Hb}$ level[12], length of hospital stay[13, 14], anesthesia method during operation, etc. [11]. The speed of operation completion has long been considered as a way to evaluate the surgeon's ability. The surgeon Robert Liston has been highly praised for being able to complete the amputation above the knee in less than 2.5 minutes. Although the development of modern anesthesiology avoids the requirement that surgeons must complete the operation as quickly as possible, they still bear the pressure of reducing the operation duration. Another reason behind this is to increase the number of hospital admissions [15].

At present, the association between the operation duration of TKA and the risk of blood transfusion is controversial. It is generally believed that shorter operation duration can reduce the risk of infection and blood transfusion, thus improving the prognosis. The research of Young et al.[16] have shown that longer operation duration is significantly related to higher revision rate and poor prognosis. However, there is no study to evaluate the influence of operation duration on the risk of blood transfusion. Hence, based on the data of single-center retrospective cohort study in Singapore, we conducted a secondary analysis to explore the association between TKA operation duration and blood transfusion.

\section{Methods}

\section{Data Sources}

The original data has been uploaded to "DATADRYAD" website (www. datadryad.org) by Abdullah et al., who have authorized DataDryad website to own the original data; Therefore, we can use these data to make a secondary analysis of different hypotheses without infringing the author's rights.

This study was a secondary analysis based on single-center retrospective cohort study in Singapore. A total of 2,622 patients underwent TKA. The demographic characteristics (age, gender, race, BMI), preoperative $\mathrm{Hb}$ level, anesthesia method, comorbidity, $\mathrm{Cr}$ in the past 60 days $>2 \mathrm{mg} / \mathrm{dl}(177 \mathrm{umol} / \mathrm{L})$, knee replacement mode, operation duration, operation date were collected. The measurement window period of $\mathrm{Hb}$ level was determined to be a maximum of 14 days and a minimum of 1 day before operation. Perioperative blood transfusion was defined as blood transfusion from 2 weeks before operation to 2 weeks after operation. We further divided the duration of the operation into groups by 100 minutes.

The study was approved by the Ethics Committee of the Affiliated Hospital of Qingdao University. The Ethics Committee particularly approved that informed consent was not required because of being approved by the “DATADRYAD”Web site (www.datadryad.org) and data were analyzed anonymously.The ethics committee waived the requirement for informed consent from all patients. 


\section{Study Variables}

The independent variable was the operation duration (minutes), and the dependent variable was whether patients had blood transfusion during the perioperative period. Perioperative blood transfusion was defined as 2 weeks before operation and 2 weeks after operation. The covariates included gender, age, race, $\mathrm{BMI}$, smoking status, preoperative $\mathrm{Hb}$ level, ASA-status, DM, IHD, CHF, CVA, anesthesia method, $\mathrm{Cr}$ in the past 60 days $\geq 2 \mathrm{mg} / \mathrm{dl}$ ( $177 \mathrm{umol} / \mathrm{L}$ ), operation mode, operation duration and operation date. Except aspirin, all antiplatelet drugs were routinely stopped for a period of time before operation. On the first day after operation, 40mg of low molecular weight heparin (Sanofi, France, Paris) was used for chemoprevention of thromboembolism until discharge. In the original study, the blood transfusion was defined as the $\mathrm{Hb}$ level of blood serum lower than $8.0 \mathrm{~g} / \mathrm{dL}$. For patients with anemia symptoms or any anemia-related organ dysfunction, the $\mathrm{Hb}$ level of blood serum lower than $10.0 \mathrm{~g} / \mathrm{dL}$ was considered as a trigger factor for blood transfusion. The measurement and evaluation of anesthesia method, blood transfusion and other covariates were described in detail in the original study.

\section{Statistical Analyses}

For the demographic characteristics of patients, we displayed the continuous variables in the form of mean and standard deviation, and further tested the differences between groups by single-factor ANOVA or Kruskal-Wallis's Htest (continuous variables of normal or skewed distribution). If the variables were classified data (percentage), we employed chi-square test. Through single-factor logistic regression analysis, We preliminarily explored the influencing factors of perioperative blood transfusion, and further analyzed the association between them by subgroup analysis to study whether there were differences between different subgroups and find out whether there were special people.

Finally, we constructed three logistics regression models: 1 . Unadjusted model; 2 . Partially adjusted model; 3 . Completely adjusted model. Among them, age, gender, BMI and ethnicity were adjusted in the partially adjusted model. In the completely adjusted model, all the co-variables were adjusted, and the operation duration was divided into groups by 100 minutes. Further, the trend test was carried out to identify whether the association between them was stable, and $\mathrm{P}<0.05$ was considered statistically significant.Statistical packages R, version 3.4 .3 (http://www.r-project.org) and EmpowerStats software (http://www.empowerstats.com, X\&Y Solutions, Inc.) were used for statistical analyses.

\section{Results}

\section{The Baseline characteristics of participants}

Finally, a total of 2,622 patients underwent TKA. 153 patients (5.8\%) had perioperative blood transfusion, and 2,469 patients $(94.2 \%$ ) had no perioperative blood transfusion (Table 1$)$. Compared with the age of patients who had no perioperative blood transfusion $(66.066 \pm 8.094)$, the age of patients who had perioperative blood transfusion was larger $(69.373 \pm 9.642)$, and the difference was statistically significant $(p<0.001)$ (Table 1). There was no significant difference $(P>0.05)$ (Table 1$)$ between the two groups in 
gender, race, smoking status, DM, DM on insulin, IHD, CVA, operation date, while there was significant difference $(\mathrm{P}<0.05)$ (Table 1$)$ in $\mathrm{BMI}$, preoperative $\mathrm{Hb}$ level, ASA status, OSA, CHF, $\mathrm{Cr}$ in the past 60 days> $2 \mathrm{mg} / \mathrm{dl}(177 \mathrm{umol} / \mathrm{L})$, operation mode, operation duration and anesthesia method.

\section{Table 1 Baseline characteristics of selected participants}


Whether blood transfusion in the perioperation?
No Yes

प2469]

प153[
P- P-

value value*

0.437

$601(24.342 \%) \quad 33(21.569 \%)$

$1868 \quad 120$

(75.658\%) (78.431\%)

Age(Years)

$66.066 \pm$

8.094

$69.373 \pm$

9.642

$<0.001<0.001$

Race

Chinese

Indian

Malay

Others

BMI

$H b(g / d L)$

ASA Status

1

2

3

Type of Anaesthesia

GA

RA

Procedure Description

Unilateral

Bilateral

Revision

Smoking
$0.364 \quad-$

127

(83.007\%)

(84.204\%)

$9(5.882 \%)$

$179(7.250 \%) \quad 9(5.882 \%)$

$70(2.835 \%) \quad 8(5.229 \%)$

$27.886 \pm$

5.587

$26.592 \pm$ 4.956

$0.005<0.001$

$13.160 \pm$ 1.394

$12.013 \pm$ 1.796

$<0.001<0.001$ $<0.001$

$179(7.250 \%) \quad 5(3.268 \%)$

$2151 \quad 123$

(87.120\%) (80.392\%)

$139(5.630 \%) \quad 25(16.340 \%)$

$<0.001 \quad-$

$884(35.804 \%) \quad 77(50.327 \%)$

1585

(64.196\%)

76 (49.673\%)

$<0.001$

\begin{tabular}{|c|c|}
\hline $\begin{array}{l}2273 \\
(92.062 \%)\end{array}$ & $\begin{array}{l}121 \\
(79.085 \%)\end{array}$ \\
\hline 176 (7.128\%) & 30 (19.608\%) \\
\hline $20(0.810 \%)$ & $2(1.307 \%)$ \\
\hline
\end{tabular}

0.119 


\begin{tabular}{|c|c|c|c|c|}
\hline No & $\begin{array}{l}2230 \\
(90.320 \%)\end{array}$ & $\begin{array}{l}144 \\
(94.118 \%)\end{array}$ & & \\
\hline Yes & $239(9.680 \%)$ & $9(5.882 \%)$ & & \\
\hline DM & & & 0.420 & - \\
\hline No & $\begin{array}{l}2017 \\
(81.693 \%)\end{array}$ & $\begin{array}{l}121 \\
(79.085 \%)\end{array}$ & & \\
\hline Yes & $452(18.307 \%)$ & $32(20.915 \%)$ & & \\
\hline IHD & & & 0.108 & - \\
\hline No & $\begin{array}{l}2348 \\
(95.099 \%)\end{array}$ & $\begin{array}{l}141 \\
(92.157 \%)\end{array}$ & & \\
\hline Yes & $121(4.901 \%)$ & $12(7.843 \%)$ & & \\
\hline CHF & & & 0.001 & - \\
\hline No & $\begin{array}{l}2451 \\
(99.271 \%)\end{array}$ & $\begin{array}{l}148 \\
(96.732 \%)\end{array}$ & & \\
\hline Yes & $18(0.729 \%)$ & $5(3.268 \%)$ & & \\
\hline CVA & & & 0.872 & - \\
\hline No & $\begin{array}{l}2425 \\
(98.218 \%)\end{array}$ & $\begin{array}{l}150 \\
(98.039 \%)\end{array}$ & & \\
\hline Yes & $44(1.782 \%)$ & $3(1.961 \%)$ & & \\
\hline $\begin{array}{l}\text { Creatinine }>2 \mathrm{mg} / \mathrm{dl} \text { (177 umol/L) (Past } 60 \\
\text { days) }\end{array}$ & & & $<0.001$ & - \\
\hline No & $\begin{array}{l}2181 \\
(88.335 \%)\end{array}$ & $\begin{array}{l}129 \\
(84.314 \%)\end{array}$ & & \\
\hline Yes & $14(0.567 \%)$ & $6(3.922 \%)$ & & \\
\hline Missing & $274(11.098 \%)$ & $18(11.765 \%)$ & & \\
\hline DM on insulin & & & 0.096 & - \\
\hline No & $\begin{array}{l}1834 \\
(74.281 \%)\end{array}$ & $\begin{array}{l}111 \\
(72.549 \%)\end{array}$ & & \\
\hline Yes & $39(1.580 \%)$ & $6(3.922 \%)$ & & \\
\hline Missing & $596(24.139 \%)$ & $36(23.529 \%)$ & & \\
\hline which Day of doing operation in a week? & & & 0.215 & - \\
\hline Mon & 408 (16.525\%) & 27 (17.647\%) & & \\
\hline Tue & 548 (22.195\%) & 41 (26.797\%) & & \\
\hline Wed & $\begin{array}{l}428(17.335 \%) \\
\text { age } 7 / 20\end{array}$ & $20(13.072 \%)$ & & \\
\hline
\end{tabular}


Thu

Fri

Sat
$571(23.127 \%) \quad 29(18.954 \%)$

$386(15.634 \%) \quad 31(20.261 \%)$

$128(5.184 \%) \quad 5(3.268 \%)$

Results in the table: mean + SD / N (\%)

$P$ value *: if it is a continuous variable, it shall be obtained by Kruskal Wallis rank sum test. If the theoretical number of counting variables is less than 10 , it shall be obtained by Fisher exact probability test.

\section{The Single-factor analysis and subgroup analysis of operation duration and blood transfusion}

We analyzed the association between the operation duration and perioperative blood transfusion by single-factor logistics regression. The results showed that the older age $(\mathrm{OR}=1.051,95 \% \mathrm{Cl}: 1.030,1.073)$, the lower $\mathrm{BMI}$ index $(\mathrm{OR}=0.939,95 \% \mathrm{Cl}: 0.903,0.976)$, the higher ASA status (OR=6.439, $95 \% \mathrm{Cl}: 2.403$, 17.249), the lower $\mathrm{Hb}$ level $(\mathrm{OR}=0.603,95 \% \mathrm{Cl}: 0.541,0.671)$, the general anesthesia(OR=0.550, $95 \%$ $\mathrm{Cl}: 0.397,0.764)$, the Bilateral KA (OR=3.202,95\%Cl:2.087, 4.913), within CHF (OR=4.600, 95\%Cl: 1.685 , 2.563), the $\mathrm{Cr}$ in past 60 days $>2 \mathrm{mg} / \mathrm{dL}(\mathrm{OR}=7.246,95 \% \mathrm{Cl}: 2.739,19.166)$, the $\mathrm{DM}$ insulin-dependent $(\mathrm{OR}=2.542,95 \% \mathrm{Cl}: 1.054,6.132)$, the higher risk factors for perioperative blood transfusion of TKA $(P<0.05)$ (Table 2). On the contrary, gender, race, operation method, smoking status, DM, IHD, CVA, operation date were not associated with perioperative blood transfusion $(P>0.05)$ (Table 2). 
Table 2

Univariate analysis of Each variable and Risk of Blood Transfusion Events in the Perioperation

P-value

OR $(95 \% \mathrm{Cl})$

Total

\section{Gender}

MALE

FEMALE

Age(Years)

Race

Chinese

Indian

Malay

Others

BMI

ASA Status

1

2

3

$\mathrm{Hb}(\mathrm{g} / \mathrm{dL})$

Type of Anaesthesia

GA

RA

Operation Duration (mins)

Procedure Description

Unilateral

$2394(91.304 \%) \quad$ Ref

$634(24.180 \%) \quad$ Ref

$2206(84.134 \%) \quad$ Ref

$184(7.018 \%) \quad$ Ref

$961(36.651 \%) \quad$ Ref
0.43732

$<0.001$
$1988(75.820 \%) \quad 1.170(0.787,1.738)$

$1.051(1.030,1.073)$

$66.259 \pm 8.227 \quad 1.051(1.030,1.073) \quad<0.001$

$150(5.721 \%) \quad 1.045(0.520,2.098) \quad 0.90174$

$188(7.170 \%) \quad 0.823(0.412,1.646) \quad 0.58188$

$78(2.975 \%) \quad 1.871(0.881,3.973) \quad 0.10305$

$27.811 \pm 5.560 \quad 0.939(0.903,0.976) \quad \mathbf{0 . 0 0 1 4 8}$

$2274(86.728 \%) \quad 2.047(0.826,5.071) \quad 0.12160$

$164(6.255 \%) \quad 6.439(2.403,17.249) \quad 0.00021$

$13.093 \pm 1.446 \quad 0.603(0.541,0.671) \quad<0.001$

$1661(63.349 \%) \quad 0.550(0.397,0.764) \quad \mathbf{0 . 0 0 0 3 5}$

$84.875 \pm 27.492 \quad 1.014(1.009,1.019) \quad<0.00001$

Data in the table: OR $(95 \% \mathrm{Cl})$ Pvalue

Result variable: what blood transfusion in the period?

Exposure variables:Race; Gender; BMl; Age(Years); ASA Status; $\mathrm{Hb}(\mathrm{g} / \mathrm{dL})$; Type of Anaesthesia; Operation Duration (mins); Procedure Description; Smoking; OSA; DM; IHD; CHF; CVA; Creatinine > $2 \mathrm{mg} / \mathrm{dl}$; DM on insulin; which Day of doing operation in a week?

Adjust variables:None 


\begin{tabular}{|c|c|c|c|}
\hline & Total & OR (95\% Cl) & P-value \\
\hline Bilateral & 206 (7.857\%) & $3.202(2.087,4.913)$ & $<0.00001$ \\
\hline Revision & $22(0.839 \%)$ & $1.879(0.434,8.130)$ & 0.39895 \\
\hline \multicolumn{4}{|l|}{ Smoking } \\
\hline No & $2374(90.542 \%)$ & Ref & \\
\hline Yes & $248(9.458 \%)$ & $0.583(0.294,1.158)$ & 0.12347 \\
\hline \multicolumn{4}{|l|}{ DM } \\
\hline No & $2138(81.541 \%)$ & Ref & \\
\hline Yes & $484(18.459 \%)$ & $1.180(0.789,1.765)$ & 0.42021 \\
\hline \multicolumn{4}{|l|}{ IHD } \\
\hline No & 2489 (94.928\%) & Ref & \\
\hline Yes & $133(5.072 \%)$ & $1.651(0.891,3.061)$ & 0.11105 \\
\hline \multicolumn{4}{|l|}{ CHF } \\
\hline No & 2599 (99.123\%) & Ref & \\
\hline Yes & $23(0.877 \%)$ & $4.600(1.685,12.563)$ & 0.00291 \\
\hline \multicolumn{4}{|l|}{ CVA } \\
\hline No & 2575 (98.207\%) & Ref & \\
\hline Yes & $47(1.793 \%)$ & $1.102(0.338,3.591)$ & 0.87163 \\
\hline \multicolumn{4}{|c|}{ Creatinine $>2 \mathrm{mg} / \mathrm{dl}$} \\
\hline No & $2310(88.101 \%)$ & Ref & \\
\hline Yes & $20(0.763 \%)$ & $7.246(2.739,19.166)$ & 0.00007 \\
\hline NA & $292(11.137 \%)$ & $1.111(0.668,1.848)$ & 0.68600 \\
\hline \multicolumn{4}{|c|}{ DM on insulin } \\
\hline No & 1945 (74.180\%) & Ref & \\
\hline \multicolumn{4}{|c|}{ Data in the table: OR $(95 \% \mathrm{Cl})$ Pvalue } \\
\hline \multicolumn{4}{|c|}{ Result variable: what blood transfusion in the period? } \\
\hline \multicolumn{4}{|c|}{$\begin{array}{l}\text { Exposure variables:Race; Gender; BMl; Age(Years); ASA Status; Hb(g/dL); Type of Anaesthesia; } \\
\text { Operation Duration (mins); Procedure Description; Smoking; OSA; DM; IHD; CHF; CVA; Creatinine > } \\
\text { 2mg/dl ; DM on insulin; which Day of doing operation in a week? }\end{array}$} \\
\hline Adjust vari & & & \\
\hline
\end{tabular}




\begin{tabular}{|lcll|}
\hline \multicolumn{1}{|c}{ Total } & OR (95\%Cl) & P-value \\
\hline Yes & $45(1.716 \%)$ & $2.542(1.054,6.132)$ & 0.03785 \\
\hline NA & $632(24.104 \%)$ & $0.998(0.678,1.470)$ & 0.99193 \\
\hline Day of doing operation in a week? & & & \\
\hline Mon & $435(16.590 \%)$ & Ref & \\
\hline Tue & $589(22.464 \%)$ & $1.131(0.684,1.868)$ & 0.63208 \\
\hline Wed & $448(17.086 \%)$ & $0.706(0.390,1.279)$ & 0.25081 \\
\hline Thu & $600(22.883 \%)$ & $0.767(0.448,1.316)$ & 0.33614 \\
\hline Fri & $417(15.904 \%)$ & $1.214(0.711,2.071)$ & 0.47770 \\
\hline Sat & $133(5.072 \%)$ & $0.590(0.223,1.564)$ & 0.28896 \\
\hline Data in the table: OR (95\%Cl) Pvalue & & & \\
\hline Result variable: what blood transfusion in the period? & & \\
\hline $\begin{array}{l}\text { Exposure variables:Race; Gender; BMl; Age(Years); ASA Status; Hb(g/dL); Type of Anaesthesia; } \\
\text { Operation Duration (mins); Procedure Description; Smoking; OSA; DM; IHD; CHF; CVA; Creatinine > }\end{array}$ & \\
\hline 2mg/dl ; DM on insulin; which Day of doing operation in a week? & & \\
\hline Adjust variables:None & & & \\
\hline
\end{tabular}

We further conducted stratification analysis on the age, BMI group, ASA status and $\mathrm{Hb}$ group. We observed that the incidence of perioperative blood transfusion was higher $(P<0.05)($ Table 3$)$ when the $\mathrm{BMI}$ of patients was less than $29 \mathrm{~kg} / \mathrm{m}^{2}$. Moreover, in the stratified analysis of age, ASA status and $\mathrm{Hb}$, we found that the older the patients, the higher the ASA status and the lower the preoperative hemoglobin $\mathrm{Hb}$ value, and the higher the incidence of perioperative blood transfusion (Table 3). 
Table 3

Subgroup Analysis of Operation Duration (mins) and Blood Transfusion in the Perioperation

\begin{tabular}{|c|c|c|c|}
\hline & \multirow[t]{2}{*}{$\mathbf{N}$} & Blood Transfusion & \multirow[t]{2}{*}{ P-value } \\
\hline & & OR $(95 \% \mathrm{Cl})$ & \\
\hline \multicolumn{4}{|l|}{ BMI group } \\
\hline $14.6-25.4$ & 862 & $1.019(1.011,1.027)$ & $<0.0001$ \\
\hline $25.5-29$ & 884 & $1.014(1.005,1.022)$ & 0.0022 \\
\hline $29.1-183.3$ & 876 & $1.007(0.996,1.019)$ & 0.1915 \\
\hline \multicolumn{4}{|c|}{ Age(Years) group } \\
\hline $20-62$ & 853 & $1.011(1.001,1.021)$ & 0.034 \\
\hline $63-69$ & 833 & $1.016(1.007,1.025)$ & 0.0005 \\
\hline $70-92$ & 936 & $1.016(1.008,1.024)$ & $<0.0001$ \\
\hline \multicolumn{4}{|l|}{ ASA Status } \\
\hline 1 & 184 & $1.005(0.974,1.038)$ & 0.7429 \\
\hline 2 & 2274 & $1.015(1.009,1.020)$ & $<0.0001$ \\
\hline 3 & 164 & $1.012(0.997,1.027)$ & 0.1234 \\
\hline \multicolumn{4}{|c|}{$\mathrm{Hb}(\mathrm{g} / \mathrm{dL})$ group } \\
\hline $6.8-12.5$ & 820 & $1.010(1.003,1.016)$ & 0.0062 \\
\hline $12.6-13.6$ & 920 & $1.024(1.014,1.035)$ & $<0.0001$ \\
\hline $13.7-18.1$ & 882 & $1.013(1.001,1.025)$ & 0.0288 \\
\hline
\end{tabular}


Table 4

Univariate and multivariate analysis of Operation Duration (mins) and Blood Transfusion in the perioperation

\begin{tabular}{|c|c|c|c|}
\hline \multirow[t]{3}{*}{ Exposure } & Non-adjusted Model & Adjust I Model & Adjust II Model \\
\hline & OR $(95 \% \mathrm{Cl})$ & OR $(95 \% \mathrm{Cl})$ & OR $(95 \% \mathrm{Cl})$ \\
\hline & P-value & P-value & P-value \\
\hline $\begin{array}{l}\text { Operation Duration } \\
\text { (mins) }\end{array}$ & $\begin{array}{l}1.014(1.009,1.019) \\
<0.00001\end{array}$ & $\begin{array}{l}1.016(1.011,1.021) \\
<0.00001\end{array}$ & $\begin{array}{l}1.011(1.004,1.018) \\
0.00096\end{array}$ \\
\hline \multicolumn{4}{|l|}{ Group } \\
\hline$<100$ & Ref & Ref & Ref \\
\hline$>=100$ & $\begin{array}{l}1.947(1.393,2.722) \\
0.00010\end{array}$ & $\begin{array}{l}2.161(1.537,3.039) \\
<0.00001\end{array}$ & $\begin{array}{l}1.568(1.034,2.378) \\
0.03442\end{array}$ \\
\hline P for trend & 0.00010 & $<0.00001$ & 0.03442 \\
\hline \multicolumn{4}{|c|}{ Result variable: what blood transfusion in the period? } \\
\hline \multicolumn{4}{|c|}{$\begin{array}{l}\text { Exposure variables:Operation Duration (mins); Operation Duration (mins) 怄; Operation Duration } \\
\text { (mins) }\end{array}$} \\
\hline \multicolumn{4}{|c|}{ Non-adjusted model adjust for: None } \\
\hline \multicolumn{4}{|c|}{ Adjust I model adjust for: Race; Gender; BMl; Age(Years) } \\
\hline \multicolumn{4}{|c|}{$\begin{array}{l}\text { Adjust II model adjust for: Race; Gender; BMl; Age(Years); ASA Status; } \mathrm{Hb}(\mathrm{g} / \mathrm{dL}) \text {; Type of Anaesthesia; } \\
\text { Procedure Description; Smoking; OSA; DM; IHD; CHF; CVA; Creatinine > 2mg/dl (177 umol/L) (Past } 60 \\
\text { days); DM on insulin; which Day of doing operation in a week? }\end{array}$} \\
\hline
\end{tabular}

\section{The Multiple Logistics Regression Operation Duration And Blood Transfusion}

Finally, we explored the independent influence of operation duration and perioperative blood transfusion by multi-factor logistics regression. It was found there was a positive association between operation duration and perioperative blood transfusion in the three models, and the relationship was stable. In the unadjusted model, the risk of blood transfusion would increase by $1.4 \%$ for each 1-minute increase in operative duration ( $\mathrm{OR}=1.014,95 \% \mathrm{Cl}$ : $1.009,1.019)$. In the partially adjusted model, the risk of blood transfusion would increase by $1.6 \%$ for each 1 -minute increase in operative duration (OR $=1.016,95 \% \mathrm{Cl}$ : $1.011,1.021)$. In the fully adjusted model, the risk of blood transfusion would increase by $1.1 \%$ for each 1minute increase in operative duration( $\mathrm{OR}=1.011,95 \% \mathrm{Cl}$ : $1.004,1.018)$.

Compared with patients with operation duration less than 100 minutes, the incidence of perioperative blood transfusion in patients with operation duration equal to and over 100 minutes was $56.8 \%$ higher 
$(\mathrm{OR}=1.568,95 \% \mathrm{Cl}: 1.034,2.378)$, and the trend test showed that the $\mathrm{P}$ value was below 0.05 , which indicated that the positive association between the two was stable.

\section{Discussions}

Our research demonstrated that the average operation duration of patients receiving TKA was $84.875 \pm 27.492$ minutes. After adjusting the potential risk factors of blood transfusion, patients with operation duration equal to and over 100 minutes had significantly higher risk of blood transfusion compared with patients with TKA operation duration less than 100 minutes. This was consistent with the previous research results of Kevin et al.[15]. The revision rate of TKA for more than 150 minutes was significantly higher than that of the operation lasting 120-150 minutes. Studies demonstrated that the operation duration was directly proportional to the risk of blood transfusion. In this regard, measures to shorten the operation duration as much as possible would be beneficial to reduce the blood loss and the risk of blood transfusion in keen operation [17]. On the contrary, the study of Zhong et al. [11] proved that patients with operation duration equal to and over 90 minutes had a lower risk of blood transfusion than those with the operation duration of 60-89 minutes, possibly due to differences in the target group and the surgeon's skills.

Our research results showed that each 1-minute increase in operation duration increased the risk of blood transfusion by $1.1 \%$, which indicated that operation duration was one of the most important independent predictors of perioperative blood transfusion. Similarly, other studies found that longer operation duration was significantly related to higher revision rate and poor prognosis, which might be associated with complications (such as bleeding, large joint cavity, Infection, etc.)[18-22]. The complexity of the operation extended the duration of the operation, and the risk of postoperative complications increased with the high incidence of massive blood loss and transfusion. The results of a study on the operation duration and the risk of blood loss and blood transfusion in hip revision arthroplasty presented that the operation duration was the sole significant variable affecting the blood loss. The incidence of intraoperative bleeding exceeding $2000 \mathrm{ml}$ increased by $3 \%$ for each 1-minute increase in operation duration [17]. However, a co-enrolled study of 58,009 TKA patients in New Zealand found that for TKA with operation duration less than 120 minutes, further shortening the operation duration could not improve the prognosis. Meanwhile, when the operation duration was less than 40 minutes, it might in turn increase the risk of bleeding and other complications[16]. In this respect, how to shorten the operation duration has become a key control strategy for perioperative blood transfusion, requiring surgeons to control the operation duration in accordance with patient's individual situation, take measures to reduce the risk of bleeding and anemia, and minimize the risk of perioperative blood transfusion in order to obtain the ideal prognosis.

Previous research showed that the prolonged operation duration might be related to the complexity of operation, the lack of experience or operating habits of surgeons and other factors[23, 24]. In hip replacement where the operation duration exceeded 140 minutes, more than $50 \%$ of them were complex cases requiring more professional surgical skills[25]. Jonathan et al [17] discovered that the operation 
duration was related to the surgeon's experience. The average operation duration of doctor with over two years' experience would be reduced by 40 minutes, but the risk of blood loss and blood transfusion would be increased by three times. In addition, the operation duration might also be related to the obesity of patients[26-28]. Obese patients $(\mathrm{BMI} \geq 40 \mathrm{~kg} / \mathrm{m} 2)$ receiving TKA had a longer average operation duration and more intraoperative blood loss, thus increasing the incidence of blood transfusion.

This research found that gender was an independent factor affecting perioperative blood transfusion. Compared with female patients receiving TKA, the operation duration of male patients was closely related to the risk of perioperative blood transfusion, which was contrary to the results of previous studies[11].Nevertheless, no study discussed the reason why gender was associated with the risk of blood transfusion. In addition, our results were consistent with those of other studies in that the older patients had higher risk of blood transfusion[29-32]. Older people tend to be in poor health and are more likely to experience heavy bleeding, increasing the incidence of perioperative blood transfusion.

Perioperative blood transfusion will lead to a series of potential complications, such as blood transfusion reaction, management errors, infection risks (blood transmission and periprosthetic infection)[33, 34], increasing costs, etc. It is our future research direction to significantly reduce patients' demand for blood transfusion. Some studies on the use of closed drainage in hip or knee replacement have shown that the use of drainage tube has a high risk of blood transfusion, which is of no help to the operation[35, 36]. Previous studies have put forward a variety of blood protection strategies, such as preoperative autologous donation, isovolumetric blood dilution, intraoperative blood recovery, etc. [28, 37], to minimize perioperative blood loss, avoid allogeneic blood transfusion and reduce various complications caused by blood transfusion.

Meanwhile, there are some limitations in our study. First, due to geographical restrictions, the target group of this study is all patients receiving TKA in Singapore, which may affect the universality of the results. Second, this study is based on the secondary analysis of observational study, so we can not adjust the variables not included in the data. In the meantime, we don't have any data about other complications affected by the operation duration, such as thromboembolism and wound complications. Furthermore, it is not clear whether the operation duration in this data only refers to the operation duration of surgeons or the combined time including anesthesia time. Finally, the blood transfusion judgment of different doctors and anesthesiologists is also a potential confounding factor.

\section{Conclusion}

Our research shows that the longer the TKA operation duration, the higher the incidence of perioperative blood transfusion. The incidence of perioperative blood transfusion increases by $66 \%$ for every 1 -hour increase in operation duration. Compared with patients with operation duration less than 100 minutes, patients with operation duration equal to and over100 minutes have an increased risk of blood transfusion by $56.8 \%$. 


\section{Abbreviations}

TKA:Total knee arthroplasty; BMl: body mass index冈Hb:hemoglobin囚ASA-PS:American Society of Anesthesiologist Physical Status ; CCF:congestive cardiac failure; CVA囚cerebrovascular accidents; DM:diabetes mellitus; GA: general anaesthesia; IHD: ischaemic heart disease; LOS: length of stay; RA: regional anaesthesia;

\section{Declarations}

\section{Data availability statement}

Availability of Data and Materials: Data can be down-loaded from "DATADRYAD" database. Dryad data package:Abdullah HR, Sim E, Hao Y, Lin G, Liew GHC, Lamoureux EL,Tan MH (2017). Data from: Association between preoperative anemia with length of hospital stay among patients undergoing primary total knee arthroplasty in Singapore:a single-center retrospective study. Dryad Digital Repository. https://doi.org/10.5061/dryad.73250.

\section{Funding}

This study was financially supported by the Department of Science Technology of Shandong Province for

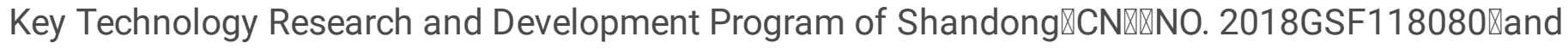
Qingdao Municipal Science and Technology Bureau for demotic science ar technology program $₫$ NO. 196-1-16-nsh $₫$

\section{Author contributions}

BL performed the data analysis. YH wrote the manuscript. JP P contributed to the manuscript revise. YH contributed to literature search and extraction. BL, and ZJ W conceived and designed the study. All authors have read and approved the final version of the manuscript.

\section{Conflict of interest}

The authors declare that the research was conducted in the absence of any commercial or financial relationships that could be construed as a potential conflict of interest.

\section{Ethics approval and consent to participate}

The study was approved by the Ethics Committee of the Affiliated Hospital of Qingdao University. The Ethics Committee particularly approved that informed consent was not required because of being approved by the DRYAD and data were analyzed anonymously. The ethics committee waived the requirement for informed consent from all patients.

\section{Consent for publication}


Not applicable.

\section{Competing interests}

The authors declare that they have no competing interests.

\section{References}

1. Maradit KH, Larson DR, Crowson CS, et al. Prevalence of total hip and knee replacement in the united states. J Bone Joint Surg Am. 2015;97(17):1386-97. https://doi.org/10.2106/JBJS.N.01141.

2. Weiser TG, Regenbogen SE, Thompson KD, et al. An estimation of the global volume of surgery: $A$ modelling strategy based on available data. Lancet. 2008;372(9633):139-44. https://doi.org/10.1016/S0140-6736(08)60878-8.

3. Hart A, Khalil JA, Carli A, Huk O, Zukor D, Antoniou J. Blood transfusion in primary total hip and knee arthroplasty. Incidence, risk factors, and Thirty-Day complication rates. Journal of Bone and Joint Surgery. 2014;96(23):1945-51. https://doi.org/10.2106/JBJS.N.00077.

4. Park JH, Rasouli MR, Mortazavi SM, Tokarski AT, Maltenfort MG, Parvizi J. Predictors of perioperative blood loss in total joint arthroplasty. J Bone Joint Surg Am. 2013;95(19):1777-83. https://doi.org/10.2106/JBJS.L.01335.

5. BMC musculoskeletal disorders BioMed central.

6. Innerhofer P, Klingler A, Klimmer C, Fries D, Nussbaumer W. Risk for postoperative infection after transfusion of white blood cell-filtered allogeneic or autologous blood components in orthopedic patients undergoing primary arthroplasty. Transfusion (Philadelphia, Pa.). 2005;45(1):103-10. https://doi.org/10.1111/j.1537-2995.2005.04149.x.

7. Jaffer AK, Barsoum WK, Krebs V, Hurbanek JG, Morra N, Brotman DJ. Duration of anesthesia and venous thromboembolism after hip and knee arthroplasty. Mayo Clin Proc. 2005;80(6):732-8. https://doi.org/10.1016/S0025-6196(11)61526-7.

8. Pedersen AB, Mehnert F, Overgaard S, Johnsen SP. Allogeneic blood transfusion and prognosis following total hip replacement: A population-based follow up study. BMC Musculoskelet Disord. 2009;10:167. https://doi.org/10.1186/1471-2474-10-167.

9. Menendez ME, Lu N, Huybrechts KF, et al. Variation in use of blood transfusion in primary total hip and knee arthroplasties. J Arthroplasty. 2016;31(12):2757-63.

https://doi.org/10.1016/j.arth.2016.05.022.

10. Kim JL, Park J, Han S, Cho IY, Jang K. Allogeneic blood transfusion is a significant risk factor for Surgical-Site infection following total hip and knee arthroplasty: A Meta-Analysis. The Journal of Arthroplasty. 2017;32(1):320-5. https://doi.org/10.1016/j.arth.2016.08.026.

11. Zhu Z, Tong P. Association between type of anesthesia and risk of blood transfusion events in primary unilateral total knee arthroplasty: A secondary analysis based on a cohort study in singapore. J Knee Surg. 2021;34(10):1120-5. https://doi.org/10.1055/s-0040-1701486. 
12. Salido JA, Marín LA, Gómez LA, Zorrilla P, Martínez C. Preoperative hemoglobin levels and the need for transfusion after prosthetic hip and knee surgery: Analysis of predictive factors. Journal of bone and joint surgery. American volume. 2002;84(2):216-20. https://doi.org/10.2106/00004623200202000-00008.

13. Browne JA, Adib F, Brown TE, Novicoff WM. Transfusion rates are increasing following total hip arthroplasty: Risk factors and outcomes. The Journal of Arthroplasty. 2013;28(8):34-7. https://doi.org/10.1016/j.arth.2013.03.035.

14. Abdullah HR, Sim YE, Hao Y, et al. Association between preoperative anaemia with length of hospital stay among patients undergoing primary total knee arthroplasty in Singapore: A single-centre retrospective study. Bmj Open. 2017;7(6):e16403. https://doi.org/10.1136/bmjopen-2017-016403.

15. Ong KL, Lau E, Manley M, Kurtz SM. Effect of procedure duration on total hip arthroplasty and total knee arthroplasty survivorship in the united states medicare population. The Journal of Arthroplasty. 2008;23(6):127-32. https://doi.org/10.1016/j.arth.2008.04.022.

16. Young SW, Mutu-Grigg J, Frampton CM, Cullen J. Does speed matter? Revision rates and functional outcomes in TKA in relation to duration of surgery. J Arthroplasty. 2014;29(7):1473-7. https://doi.org/10.1016/j.arth.2014.03.004.

17. Manara J, Sandhu H, Wee M, et al. Prolonged operative time increases risk of blood loss and transfusion requirements in revision hip surgery. Eur J Orthop Surg Traumatol. 2020;30(7):1181-6. https://doi.org/10.1007/s00590-020-02677-4.

18. Peersman G, Laskin R, Davis J, Peterson M. Infection in total knee replacement: A retrospective review of 6489 total knee replacements. Clin Orthop Relat Res. 2001(392):15-23.

19. Stiehl JB, Jackson S, Szabo A. Multi-factorial analysis of time efficiency in total knee arthroplasty. Comput Aided Surg. 2009;14(1-3):58-62. https://doi.org/10.3109/10929080903030996.

20. Namba RS, Inacio MC, Paxton EW. Risk factors associated with deep surgical site infections after primary total knee arthroplasty: An analysis of 56,216 knees. J Bone Joint Surg Am. 2013;95(9):775-82. https://doi.org/10.2106/JBJS.L.00211.

21. Willis-Owen CA, Konyves A, Martin DK. Factors affecting the incidence of infection in hip and knee replacement: An analysis of 5277 cases. J Bone Joint Surg Br. 2010;92(8):1128-33. https://doi.org/10.1302/0301-620X.92B8.24333.

22. Kessler S, Kinkel S, Kafer W, Puhl W, Schochat T. Influence of operation duration on perioperative morbidity in revision total hip arthroplasty. Acta Orthop Belg. 2003;69(4):328-33.

23. Smabrekke A, Espehaug B, Havelin LI, Furnes O. Operating time and survival of primary total hip replacements: An analysis of 31,745 primary cemented and uncemented total hip replacements from local hospitals reported to the Norwegian Arthroplasty Register 1987-2001. Acta Orthop Scand. 2004;75(5):524-32. https://doi.org/10.1080/00016470410001376.

24. Ong KL, Lau E, Manley M, Kurtz SM. Effect of procedure duration on total hip arthroplasty and total knee arthroplasty survivorship in the United States Medicare population. J Arthroplasty. 2008;23(6 Suppl 1):127-32. https://doi.org/10.1016/j.arth.2008.04.022. 
25. Foote J, Panchoo K, Blair P, Bannister G. Length of stay following primary total hip replacement. The Annals of The Royal College of Surgeons of England. 2009;91(6):500-4. https://doi.org/10.1308/003588409X432356.

26. Namba RS, Paxton L, Fithian DC, Stone ML. Obesity and perioperative morbidity in total hip and total knee arthroplasty patients. The Journal of Arthroplasty. 2005;20:46-50. https://doi.org/10.1016/j.arth.2005.04.023.

27. Zarin J, Grosvenor D, Schurman D, Goodman S. Efficacy of intraoperative blood collection and reinfusion in revision total hip arthroplasty. Journal of bone and joint surgery. American volume. 2003;85(11):2147-51. https://doi.org/10.2106/00004623-200311000-00013.

28. Zarin J, Grosvenor D, Schurman D, Goodman S. Efficacy of intraoperative blood collection and reinfusion in revision total hip arthroplasty. J Bone Joint Surg Am. 2003;85(11):2147-51. https://doi.org/10.2106/00004623-200311000-00013.

29. Maiorano E, Bodini BD, Cavaiani F, Pelosi C, Sansone V. Length of stay and short-term functional outcomes after total knee arthroplasty: Can we predict them? Knee. 2017;24(1):116-20. https://doi.org/10.1016/j.knee.2016.09.022.

30. Ong PH, Pua YH. A prediction model for length of stay after total and unicompartmental knee replacement. Bone Joint J. 2013;95-B(11):1490-6. https://doi.org/10.1302/0301620X.95B11.31193.

31. Jonas SC, Smith HK, Blair PS, Dacombe P, Weale AE. Factors influencing length of stay following primary total knee replacement in a UK specialist orthopaedic centre. Knee. 2013;20(5):310-5. https://doi.org/10.1016/j.knee.2012.07.010.

32. Tan C, Loo G, Pua YH, et al. Predicting discharge outcomes after total knee replacement using the Risk Assessment and Predictor Tool. Physiotherapy. 2014;100(2):176-81. https://doi.org/10.1016/j.physio.2013.02.003.

33. Walsh TS, Palmer J, Watson D, et al. Multicentre cohort study of red blood cell use for revision hip arthroplasty and factors associated with greater risk of allogeneic blood transfusion. Br J Anaesth. 2012;108(1):63-71. https://doi.org/10.1093/bja/aer326.

34. Tornero E, Pereira A, Bravo J, et al. Transfusion of packed red blood cells stored $>14$ days was associated with a higher risk of infection after hip revision arthroplasty. Hip Int. 2016;26(2):132-7. https://doi.org/10.5301/hipint.5000324.

35. Parker MJ, Roberts CP, Hay D. Closed suction drainage for hip and knee arthroplasty. A metaanalysis. J Bone Joint Surg Am. 2004;86(6):1146-52. https://doi.org/10.2106/00004623200406000-00005.

36. Walmsley PJ, Kelly MB, Hill RM, Brenkel I. A prospective, randomised, controlled trial of the use of drains in total hip arthroplasty. J Bone Joint Surg Br. 2005;87(10):1397-401. https://doi.org/10.1302/0301-620X.87B10.16221.

37. Park KJ, Couch CG, Edwards PK, Siegel ER, Mears SC, Barnes CL. Tranexamic acid reduces blood transfusions in revision total hip arthroplasty. J Arthroplasty. 2016;31(12):2850-5. 
https://doi.org/10.1016/j.arth.2016.05.058.

Page 20/20 